\title{
The Framework Convention on Tobacco Control
}

\author{
Luiz Felipe de Seixas Corrêa'
}

The Framework Convention on Tobacco Control (FCTC) has been under negotiation in Geneva for more than two years now. When in force, it will be the first convention ever negotiated under the auspices of the World Health Organization. It constitutes a unique and innovative public health instrument that aims at curbing the escalation of smoking and other forms of tobacco use in order to prevent tobacco-related illness and death. It thus represents the opportunity to save millions of lives and to afford future generations fuller enjoyment of their right to health protection. Through this instrument we aim at mobilizing governments worldwide to coordinate their policies in order to deal with the many different requirements of tobacco control.

Today, approximately $48 \%$ of the men and $12 \%$ of the women in the world smoke. The latest data released by the World Health Organization indicate that the number of tobacco-related deaths has jumped from 4.2 million a year to 4.9 million in the last two years (1). This means that now more than nine lives are lost every minute due to tobacco consumption. It has been scientifically proved that tobacco causes over 20 categories of fatal and disabling disease, including lung cancer, cardiovascular and chronic respiratory diseases. Despite all this evidence, tobacco consumption continues to grow. In the early 1990s there were 1100 million individuals worldwide who used tobacco. By 2000, this number had increased to almost 1300 million (2). WHO estimates that if this expansion continues, the number of tobacco-related deaths will reach more than 9 million deaths a year in 2020 (1). The vast majority of these deaths (around 70\%) will occur in the developing world, thereby placing an undue burden on societies already struggling against poverty to build viable health systems.

Women and the young are taking up smoking in higher numbers and almost half of the world's children are exposed to second-hand smoke. One out of two children who start smoking today will eventually die of a tobacco-related disease. Despite all this, marketing and advertising strategies in poor and rich countries alike promote the view that smoking is normal behaviour.

The FCTC is a global response to a global menace, requiring, as has been the case in other areas the development of conventional international law. By setting up standards and establishing a framework for international cooperation on tobacco control, we are in fact striving to establish a global regulatory system that, when in force, will stimulate, organize and supplement national policies, as well as being in itself a multilateral regime to combat the tobacco pandemic. Its successful completion and adoption would herald a new era in the field of international cooperation. Since it will cover an area that so far has been mainly in the internal domain of states, it will set high standards for the evolving multilateral system of the 21 st century. It will be extremely important from the public health perspective, which constitutes its main objective. But it will certainly also be relevant from a global political perspective, as it will enhance multilateralism over unilateralism in meeting global challenges.

Over the past years, the FCTC process has already lent impetus to policies at the national level: cross-cutting national commissions have been set up, as well as national tobacco control programmes. These are vital initiatives to assess needs and propose solutions to the terrible public health problem each of our countries faces as a result of tobacco consumption. Many surveys indicate that there is strong public support from smokers and non-smokers alike for governmental and international tobacco control policies. This should serve as a powerful encouragement for putting in place an effective Framework Convention.

In the first four negotiating sessions of the FCTC, substantial progress was made in formulating relevant proposals for the Convention. All the input needed on the different areas related to tobacco control was gathered and discussed. At the fifth session of the Intergovernmental Negotiating Body (INB), which took place in October this year, there was a breakthrough in the process. A new
"Chair's text" that I issued under my own responsibility provided the momentum to change gears and begin the actual process of negotiation, allowing delegations to get to grips with some of the core issues in the text. We were able to find appropriate language to generate consensus in some areas, notably in the clause on illicit trade, while in other parts of the text differences have been substantially narrowed. Some divergences still persist on a limited number of issues, which is natural in this type of negotiation, but they became clearer and more identifiable in the discussions. Members now benefit from a better understanding of one another's concerns, aspirations and commitments. On the basis of these discussions I will draft a revised text for consideration by INB next February.

I am confident that we will be able to move the process speedily ahead in order to meet the final objective of having a convention ready for adoption by the next World Health Assembly in May 2003. The moment has come for jointly applying the imagination and skills of all concerned to the task of producing a formulation that is generally acceptable. In order to do so, we must go beyond country perspectives and really aim for the collective interest, bringing whatever is necessary and desirable in terms of public health into the realm of the possible.

From this perspective, it is important to keep in mind that the Convention will not be the end of a process. It should be viewed rather as the first formal institutional step on the long road towards consolidating a multilateral regime on tobacco control. To achieve this, it is essential to work as much as possible on a consensus basis during the negotiations, so that the final outcome will be a convention that is both meaningful in setting public health international standards and ratifiable by the great majority of States.

1. The World Health Report 2002 — reducing risks, promoting healthy life. Geneva: World Health Organization; 2002.

2. Secretary General's Report to the Economic and Social Council (ECOSOC) on the activities of the United Nations Ad-Hoc Interagency Task Force on Tobacco Control, 2002. http://www.un.org/ esa/coordination/ecosoc/SG_UNTF_ECOSOC.pdf

\footnotetext{
${ }^{1}$ Ambassador, Permanent Representative of Brazil in Geneva, Chair of the International Negotiating Body of the Framework Convention on Tobacco Control, avenue Louis Casai 71, 1216 Cointrin, Geneva, Switzerland.

Ref. No. 02804
} 